\title{
Significant Correlation Study between Cause and Effect of Hand Arm Vibration Exposure among Grass Cutters
}

\author{
N.A. Azmir ${ }^{1, *}$, M.H. Ali ${ }^{2}$, M.N. Yahya ${ }^{1}$, I. Zaman ${ }^{1}$, M.H. Zainulabidin ${ }^{1}$, M.A. Madlan ${ }^{1}$, M. Ismon ${ }^{1}$, and M.Z. Kasron ${ }^{1}$ \\ ${ }^{1}$ Noise, Vibration \& Acoustic - Research Group (NOVIA), Faculty of Mechanical \& Manufacturing Engineering, Universiti Tun \\ Hussein Onn Malaysia, Johor, 86400, Malaysia \\ ${ }^{2}$ OSH Management Division, CRD Department, National Institute of Occupational Safety \& Health (NIOSH), Bandar Baru Bangi, \\ Selangor, 43650, Malaysia
}

\begin{abstract}
Prolonged exposures to hand-transmitted vibrations from grass-cutting machines have been associated with increasing occurrences of signs of occupational diseases related to the hand-arm vibration syndrome (HAVS). However, there are no specific studies available that cover the health cause-effects of the hand arm vibration risk factors during onsite operations. Therefore, the main objectives of this study are to determine the significant correlation of the objective and subjective measurement variables of the hand arm vibration exposure on hand arm vibration symptoms and disorders. The study was conducted for evaluation of the cause and effect for categorical and continuous variables. Significant sub symptoms element consists of neurological, vascular, musculoskeletal and awareness. Meanwhile, significant sub disorder element consists of loss of hand grip strength and finger blanching that induces to HAVS. The highest correlation significant variable was worked repeatedly done with the forearms and hand with uncomfortable hand position or grip with the value of 0.431 . Thus, the cause and effect able to monitor health condition particularly at workers hand due to hand-transmitted vibrations among grass cutters.
\end{abstract}

\section{Introduction}

Hand-transmitted vibration (HTV) is a common physical hazard for occupational safety and health which is caused by harmful activities to workers who use vibrating equipment in their routine tasks [1]. The fundamental HTV evaluation is often an initial process for employers to evaluate hand-transmitted assessment due to the hand arm vibration hazard at workplace among their employees [2-4]. With this evaluation, it will assist the employers to measure whether the works or activities are exposed to risk factor that could induce hand arm vibration syndrome (HAVS). By measuring the HTV exposure towards health cause-effect factors; it also assists the employers to decrease the cost of occupational rehabilitations and work-related injuries [57]. In European countries, there is a regulatory requirement to perform HTV exposure at workplace in which to improve employees' health quality and this can be associated to the responsibility and accountability of employers [3,4].

It is an important requirement for the risk measurement, evaluation and assessment of hand arm vibration exposure among hand-held vibrating machine workers to be taken in the monitoring process of the safety and health management $[1,2,6]$. The rationale of this study was established from occupational hand arm vibration knowledge for epidemiological methods used to identify and analyze the health cause-effects induce in a work related with vascular, neurological and musculoskeletal disorders at workplace. Hence, its principle method is to define a categorical and continuous measures linked with the development of hand arm vibration syndrome (HAVS) which has a significant element for HTV in developing the health cause-effect of hand arm vibration exposure in Malaysia [8-12]. The investigation of hand arm vibration exposure to the health cause-effect associated to the HAVS is becoming a major interest for both human factor and occupational health in conducting their research study [10-12].

Hand arm vibration syndromes (HAVS) are a prevalence health difficulty and a main cause of permanent or temporary hand disabilities [13]. Combinations of physiology, psychology and physics vibration risk factors are connected to the development of HAVS. Hand arm vibration risk factors are based on magnitude, frequency, direction and duration of vibration exposure energy to the hand palm while performing the hand-held vibrating equipment [14]. Previous studies have shown that the hand-transmitted vibration effects of HAVS are significant consequences to the vascular disorders, neurological disorders and loss of hand grip strength [15].

Safety and health cause-effect do important procedure for employers and employees to understand how to mitigate the HTV hazard which can benefit grass-cutting operators. Research has been recognized on human response to hand arm vibration measures, but has not investigated categorical and continuous data in

*Corresponding author: azali@uthm.edu.my 
correlation with health cause-effect among hand-held grass-cutting workers. Additionally, subjective surveys of HAVS have been proposed by scholars in Malaysia, yet no one has looked at classifying both hand numerical scoring and hand grip strength assessment at the same time. Thus the objective of this research is determining the significant correlation of categorical and continuous measurement variables on hand arm vibration symptoms and disorders.

\section{Methodology}

The study received written approval from the subcontractors prior to their participation in the study. Information on HAVS symptoms was obtained from interviews and physical observation or explanations to determine the presence of a condition in which workers experience HAVS after working with vibrating equipment. Workers were briefed as to the purpose of the questionnaires and were asked to complete through face-to-face interview. In this process, the interviewees selected the proper answers based on their professional judgements and subjects' feedback in order to prevent misunderstandings. Workers had no knowledge that they would later be interviewed or observed. This will provide true information in answering the HAVS questionnaire. All the information granted was confidential and used only for occupational vibration engineering research activities.

A total of 204 hand-held grass-cutting workers were selected for the study within August 2013 to June 2014. The workers were selected from general cutting operation locations involving flats, sloped and drain areas; the jobs performed at expressway median and verge as well as expressway facility buildings such as rest and service area. Some of the workers were employed full time as grass cutters, while some workers make grass cutting as their part time routine work for maintaining building facilities.

All subjects chosen were interviewed using a modified questionnaire adopted from the HandTransmitted Vibration Health Surveillance - Initial Questionnaire and Clinical Assessment published by the Research Network on Detection and Prevention of Injuries due to Occupational Vibration Exposure [16]. Some of the questions in the questionnaire were based on a study of HAVS among a group of construction workers in Malaysia [9], which was found to be reliable and applicable for different work activities. The interviews were conducted based on personal identification, social history, occupational health, occupational history, machine safety inspection and symptoms.

The personal identification information consists of name, work location, age, nationality, height $(\mathrm{m})$, weight $(\mathrm{kg})$, and types of grass cutting machine. Besides that, nominal questions such as workers' dominant hand, marital status and academic level need to be answered by workers. These sorts of questions are able to find information regarding workers' demographic detail. To determine the workers' social history, questions such as
"Do you smoke or drink alcoholic beverages", any hobby involving vibration tool and work experience involving neurotoxic chemicals have also been asked. The example of workers' health questions are;

(1) Have you ever sustained an injury to your arm or hand;

(2) Do you suffer from any long-term medical illness;

(3) Are you taking any long-term medication;

(4) Are you exposed to organic solvent chemical (e.g. nhexane).

Subjects were asked to specifically recall any sustained injury to the body and the healing process to regain normal health conditions.

Occupational history sub questions include working experience with hand-held grass-cutter, exposure to hand-held grass cutter (cutting hours) for 1 day, and the scale questions which require workers to choose either "Yes" or "No":

(1) Is work repeatedly done with the forearms and hands with twisting movement;

(2) Is work repeatedly done with the forearms and hands with forceful movement;

(3) Is work repeatedly done with the forearms and hands with uncomfortable hand position / grips.

This sort of questions can determine the musculoskeletal disorder or ergonomic problem due to repetitive and forceful tasks. Since vibration comes from the hand-held grass-cutting machine itself, the machine's safety inspection questions have been introduced. The questions are;

(1) Do you inspect the entire machine for loss of parts and any damage;

(2) Repair or replace as necessary before using the machine;

(3) Clean and maintain the machine completely after operation.

Similar scale answer required which is "Yes" or "No".

During physical observation, the author looked for colour changes in finger phalanges or finger blanching and any skin abnormalities at hand palm before workers started their work. Details on the health effects information, including colour changes on hands or fingers, tingling, numbness and weakness in handgrip strength for both hands were included in symptoms' identification. Besides that, health effect such as cold fingers, difficulty in picking up, handling or manipulating small objects as well as difficulty in opening tight jars were also asked. The information obtained is important to investigate the disability at hand due to grass-cutting operation. Finally, two occupational safety and health awareness questions have been asked; (1) Do you agree that regular use of vibratory tools is hazardous to your health;

(2) Are you aware of any devices that can protect you from the vibration hazard.

All the questions in symptoms' identification was based on either "Yes" or "No" answers. By simply responding to "Yes" and "No" scales are claimed to detect positive and negative state of health using questionnaire. According to Paakkonen et al., (2008), the use of questionnaires is appropriate because it is easier to get cooperation from subjects, one of the information 
gathering tools, economical, practical, as well as effective.

\section{Results}

In determining the significant variables, the selection of the variables has followed an output result from the data correlation significant test $(\alpha=0.05)$ and supported by extensive review on scientific literature. The collection of epidemiological evidence of the hand arm vibration disease variables was identified. The total mean of age of the participants $(\mathrm{N}=204)$ was 32.15 years $(\mathrm{SD}=9.56)$ in the range between the ages of 15 to 63 and the total mean working experience was 3.37 years $(\mathrm{SD}=4.06)$ in the range between 0.1 to 30 years (Table 1 ).

Table 1. Demographic of the workers in age-group in grasscutting operation

\begin{tabular}{|c|c|c|}
\hline $\begin{array}{c}\text { Age-Group } \\
\text { (year) }\end{array}$ & $\begin{array}{c}\text { Age } \\
\text { (year) }\end{array}$ & $\begin{array}{c}\text { Working Experience } \\
\text { (year) }\end{array}$ \\
\cline { 2 - 3 } & Mean & Mean \\
\hline $15-24(\mathrm{~N}=46)$ & 21.96 & 1.76 \\
\hline $25-29(\mathrm{~N}=56)$ & 26.96 & 2.56 \\
\hline $30-34(\mathrm{~N}=32)$ & 31.56 & 3.29 \\
\hline $35-39(\mathrm{~N}=28)$ & 36.89 & 4.07 \\
\hline $40-44(\mathrm{~N}=10)$ & 41.30 & 8.45 \\
\hline $45-49(\mathrm{~N}=19)$ & 46.37 & 4.15 \\
\hline $50-54(\mathrm{~N}=7)$ & 50.57 & 6.21 \\
\hline $55-59(\mathrm{~N}=4)$ & 55.50 & 3.75 \\
\hline $60-65(\mathrm{~N}=2)$ & 63.00 & 10.75 \\
\hline
\end{tabular}

\subsection{Categorical Variables}

The selection of the significant variables based on the categorical data from the questionnaires such as the work location, suffering from any long-term medical illness together with types of illness, any sustained injury at arm or hand, repeated works with forearms and hands with uncomfortable positions or grips, academic level, types of grass cutting machine and maintaining the machine after operation. For the health effect due to grass cutting machine, four symptoms were determined to be associated with the occupational disease: vascular, neurological, musculoskeletal and awareness. All variables were selected by correlation coefficient and significant level with contribution to hand arm vibration syndrome. Fig. 1 shows the significant inclusive sub symptoms associated to categorical cause-effect variables. The outcomes from the significant variables correlate cause effect study had revealed that the subsymptoms consists of neurological sign due to tingling and numbness, vascular sign due to finger colour change, musculoskeletal sign due to work repeatedly and awareness sign due to less information related to occupational exposure using hand-held machines.

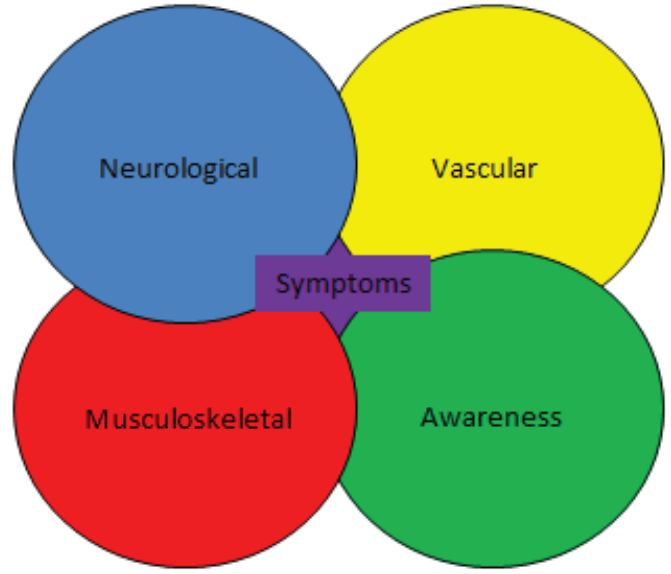

Fig. 1. Significant sub symptoms element that induces to HAVS.

\subsubsection{Vascular Symptoms}

During the selection of significant cause that affects the finger colour change, the work location or process indicates the weak positive correlation, 0.201 with the significant level of 0.007 . In addition, the vascular symptoms were also associated with suffering any long term medical illness such as shoulder pain, itchy, hot body, back pain, foot pain, waist pain, chest pain and knee pain. There is a very weak positive correlation, 0.159 coefficient of these pain associated with finger blanching due to hand-transmitted vibration generated from the back pack of grass cutting machine. Table 2 shows the correlation coefficient and significant level associated with finger colour change of the vascular symptoms.

Table 2. Formatting sections, subsections and subsubsections

\begin{tabular}{|l|c|c|}
\hline \multicolumn{1}{|c|}{ Cause / Variables } & $\begin{array}{c}\text { Correlation } \\
\text { coefficient }\end{array}$ & Significant level \\
\hline Work location & 0.201 & 0.007 \\
\hline $\begin{array}{l}\text { Suffer from any long- } \\
\text { term medical illness }\end{array}$ & 0.159 & 0.032 \\
\hline Type of illness & 0.176 & 0.017 \\
\hline
\end{tabular}

\subsubsection{Neurological Symptoms}

Repeated works from forearms and hand movement contribute to incapacity of hand movement which is exposed to high risk level. Thus, the prevalence of neurological symptoms was $20 \%$ and $18 \%$ for finger tingling and finger numbness, respectively. During the selection of significant cause variables due to sensation of numbness and tingling at fingers, the work repeatedly done with the forearms and hand with uncomfortable hand position or grip indicate the medium positive correlation coefficient of 0.431 associated with tingling sensation. Meanwhile, working repeatedly also has medium positive correlation with 0.519 coefficient associated with numbness. Other cause variables had shown weak and very weak positive correlation coefficients for both neurological symptoms as shown in Table 3.

Table 3. Experience a numb and tingling sensation at fingers 


\begin{tabular}{|c|c|c|c|c|}
\hline \multirow[b]{2}{*}{$\begin{array}{c}\text { Cause / } \\
\text { Variables }\end{array}$} & \multicolumn{2}{|c|}{ Tingling sensation } & \multicolumn{2}{|c|}{ Numbness } \\
\hline & $\begin{array}{c}\text { Correlation } \\
\text { coefficient }\end{array}$ & $\begin{array}{c}\text { Significant } \\
\text { level }\end{array}$ & $\begin{array}{c}\text { Correlation } \\
\text { coefficient }\end{array}$ & $\begin{array}{c}\text { Significant } \\
\text { level }\end{array}$ \\
\hline $\begin{array}{l}\text { Work } \\
\text { location }\end{array}$ & 0.179 & 0.016 & 0.276 & 0.000 \\
\hline $\begin{array}{l}\text { Academic } \\
\text { level }\end{array}$ & 0.078 & 0.294 & 0.200 & 0.007 \\
\hline $\begin{array}{l}\text { Sustained } \\
\text { any injury } \\
\text { at arm or } \\
\text { hand }\end{array}$ & 0.235 & 0.001 & 0.215 & 0.004 \\
\hline $\begin{array}{l}\text { Suffer } \\
\text { from any } \\
\text { long-term } \\
\text { medical } \\
\text { illness } \\
\end{array}$ & 0.207 & 0.005 & 0.223 & 0.002 \\
\hline $\begin{array}{l}\text { Type of } \\
\text { illness }\end{array}$ & 0.191 & 0.010 & 0.194 & 0.009 \\
\hline $\begin{array}{l}\text { Work } \\
\text { repeatedly }\end{array}$ & 0.431 & 0.000 & 0.519 & 0.000 \\
\hline
\end{tabular}

\subsubsection{Musculoskeletal Symptoms}

The feedback from grass-cutting workers in the questionnaire indicated that the cause variables of sustained injury at hand or arm and work repeatedly were significant to cause weakness at hand grip. The left hand correlation coefficient was higher compared to right hand with the value of 0.315 and 0.208 , respectively. Both variables show weak positive correlation with high significant level. Thus, the value produced revealed that the left handle was exposed to high vibration value as compared to right handle. The correlation coefficient and significant level for both hands was shown in Table 4.

Table 4. Suffer from weakness at hand grip

\begin{tabular}{|l|c|c|c|c|}
\hline \multirow{1}{*}{$\begin{array}{c}\text { Cause/ } \\
\text { Variables }\end{array}$} & \multicolumn{2}{|c|}{ Left Hand } & \multicolumn{2}{c|}{ Right Hand } \\
\cline { 2 - 5 } & $\begin{array}{c}\text { Correlation } \\
\text { coefficient }\end{array}$ & $\begin{array}{c}\text { Significant } \\
\text { level }\end{array}$ & $\begin{array}{c}\text { Correlation } \\
\text { coefficient }\end{array}$ & $\begin{array}{c}\text { Significant } \\
\text { level }\end{array}$ \\
\hline $\begin{array}{l}\text { Sustained } \\
\text { any injury } \\
\text { at arm or } \\
\text { hand }\end{array}$ & 0.236 & 0.001 & 0.198 & 0.007 \\
\hline $\begin{array}{l}\text { Work } \\
\text { repeatedly }\end{array}$ & 0.315 & 0.000 & 0.208 & 0.000 \\
\hline
\end{tabular}

\subsubsection{Awareness Symptoms}

The occupational safety and health (OSH) awareness among hand-held grass-cutting workers on the hand arm vibration hazard is still low due to lack of supervision, instruction, training and information. Hence, the questionnaire proved that the awareness of vibratory tools which are hazardous to health significantly weak positive correlation coefficient (0.274) in respect to types of grass cutters. In the significant variables assessed by the regulatory use of vibratory tools hazardous to health, the repeated operation and maintenance of the machine were positive weak correlation $(0.298)$ and positive very weak correlation (0.186) respectively. The results of significant variables associated with awareness symptoms are shown in Table 5.

Table 5. Regular use of vibratory tools which are hazardous to health

\begin{tabular}{|l|c|c|}
\hline \multicolumn{1}{|c|}{ Cause / Variables } & $\begin{array}{c}\text { Correlation } \\
\text { coefficient }\end{array}$ & $\begin{array}{c}\text { Significant } \\
\text { level }\end{array}$ \\
\hline $\begin{array}{l}\text { Types of grass cutting } \\
\text { machine }\end{array}$ & 0.274 & 0.000 \\
\hline Work repeatedly & 0.298 & 0.000 \\
\hline $\begin{array}{l}\text { Clean and maintain the } \\
\text { machine }\end{array}$ & 0.186 & 0.012 \\
\hline
\end{tabular}

\subsection{Continuous Variables}

The significance of variables that induces to hand arm vibration exposure disorder measurement system are divided into two sections, namely the musculoskeletal disorder and the vascular and neurological disorder. Both of these disorders were measured using hand grip strength (HGS) and hand numerical scoring (HNS) assessment respectively. Fig. 2 shows the significant inclusive sub disorder associated with continuous causeeffect variables. The outcomes from the significant variables correlate cause effect study had revealed that the sub-disorders consists of loss of hand grip strength due to worker age and finger blanching due to year of exposure operating hand-held grass-cutting machine.

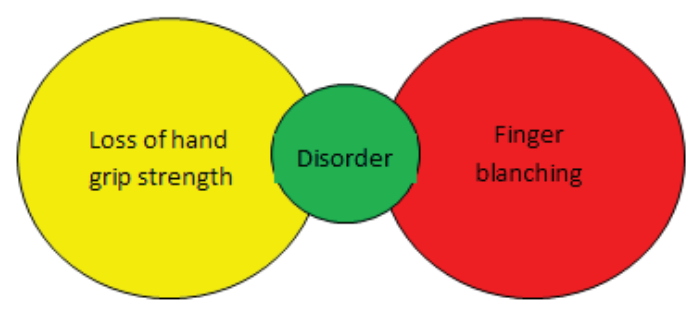

Fig. 2. Significant sub disorder element that induces to HAVS

\subsubsection{Loss of Hand Grip Strength Disorder}

The significant cause of the process among hand-held grass cutters associated with hand grip strength is categorized into two parts which are right hand and left hand. Both hands have significantly weak positive correlation which contributes to 0.392 (height) and 0.373 (weight) for right hand while 0.349 (height) and 0.353 (weight) for left hand. However, the age variable was weak negative correlation for right hand and differs from left hand. The estimated daily vibration exposure, $\mathrm{A}(8)$ has significant weak positive correlation for right hand. The value of correlation coefficient and significant level associated with hand grip strength is shown in Table 6.

Table 6. Measurement of hand grip strength force.

\begin{tabular}{|c|c|c|c|c|}
\hline \multirow[b]{2}{*}{$\begin{array}{c}\text { Cause / } \\
\text { Variables }\end{array}$} & \multicolumn{2}{|c|}{ Right hand } & \multicolumn{2}{|c|}{ Left hand } \\
\hline & $\begin{array}{c}\text { Correlation } \\
\text { coefficient }\end{array}$ & $\begin{array}{c}\text { Significant } \\
\text { level }\end{array}$ & $\begin{array}{c}\text { Correlation } \\
\text { coefficient }\end{array}$ & $\begin{array}{c}\text { Significant } \\
\text { level }\end{array}$ \\
\hline Age & -0.303 & 0.000 & 0.282 & 0.000 \\
\hline Height & 0.392 & 0.000 & 0.349 & 0.000 \\
\hline Weight & 0.373 & 0.000 & 0.353 & 0.000 \\
\hline $\begin{array}{l}\text { Right hand } \\
\text { daily } \\
\text { vibration } \\
\text { exposure, } \\
A(8)\end{array}$ & 0.249 & 0.001 & 0.105 & 0.158 \\
\hline
\end{tabular}




\subsubsection{Finger Blanching Disorder}

The significant cause of the variables for hand-held grass-cutting workers due to scoring of finger blanching disorder was separated into two parts which are left hand and right hand. Both hands indicate weak positive correlation for age and working experience with handheld grass cutter. The values of correlation coefficient and significant level, based on hand numerical scoring are shown in Table 7.

Table 7. Hand numerical scoring due to finger blanching.

\begin{tabular}{|c|c|c|c|c|}
\hline \multirow[b]{2}{*}{$\begin{array}{c}\text { Cause / } \\
\text { Variables }\end{array}$} & \multicolumn{2}{|c|}{ Right hand } & \multicolumn{2}{|c|}{ Left hand } \\
\hline & $\begin{array}{c}\text { Correlation } \\
\text { coefficient }\end{array}$ & $\begin{array}{c}\text { Significant } \\
\text { level }\end{array}$ & $\begin{array}{c}\text { Correlation } \\
\text { coefficient }\end{array}$ & $\begin{array}{c}\text { Significant } \\
\text { level }\end{array}$ \\
\hline Age & 0.386 & 0.000 & 0.257 & 0.000 \\
\hline $\begin{array}{l}\text { Cigarettes } \\
\text { per day }\end{array}$ & -0.147 & 0.048 & -0.051 & 0.498 \\
\hline $\begin{array}{l}\text { Working } \\
\text { experience }\end{array}$ & 0.344 & 0.000 & 0.337 & 0.000 \\
\hline
\end{tabular}

\section{Discussion}

The determination of the variables has been tested by data screening consisting of data normalization and significant correlation. The main objective of this analysis was to determine the significant correlation level of categorical data symptoms and continuous data disorders. The following sections discuss details of significant variables induced to HAVS categorical symptoms and continuous disorders.

\subsection{Categorical Symptoms}

An analysis selection revealed that the work repeatedly done with the forearms and hands with twisting movement showed significant medium association for neurological symptoms. According to Soo et al. (2012), the work-related fatigue initiated from repeated exertion had significant decline in muscle contractibility. This is because, the vibration propagated from the hand palm entering other body parts due to vibration intensity increases which may be due to the fact that frequency of machine vibration approaches the natural frequency of vibration at handle. In the categorical questions, the health effect is merely focusing on repeated work which significantly introduces exertion posture when operating vibrating machine. The same finding was revealed by other researchers [2,19], who observed that repeated vibration with sufficiently low magnitude gives rise to sign and symptoms of chronic disorder. Other researcher has confirmed that it is not possible to estimate symptom effects due to repeated vibration exposure at hand [20]. The determination of work repeatedly also found positive association with neurological, musculoskeletal and awareness symptoms. The study by Bovenzi (1998) in the exposure response relationship found that it was complex neurologic symptoms in the upper-limb of vibration which affects exposed workers. Griffin (1994) highlighted the same issues and found that the health symptoms of tingling and numbness as reasonable variables for predicting effects of vibration. So, work repeatedly is the most significant variable that influences hand-held grass-cutting workers for the purpose of neurological symptom.

\subsection{Continuous Disorders}

According to Griffin (2008), some preventive procedures including health surveillance at hand grip force may reduce the vibration risk. Measurement of hand grip strength is one of the useful indicators to confirm lack of upper limb disorder. In addition, the hand grip strength was best related to the age [23]. In the continuous measurement, the health effect is targeting on hand grip strength before work which is equal to normal grip force condition before exposed to vibrating equipment. The same technique was used by other researchers [24] who measure non-exposed subject to force over the test period. The study done by Kamarul et al. (2006) revealed that there may be potential cause variables which contributed to hand grip strength force based on the workers' population. Only age, weight, height, occupation and gender were correlated with hand grip strength $(\mathrm{p}<0.01)$. The determination of significant variables was the same with the study done by Kamarul et al. (2006). However, the daily vibration exposure at right hand has been added to the input selection since the study focuses on hand arm vibration disorder. Seri Rahayu et al. (2013) highlighted the same issues and found that the hand grip force is one of the factors that affects workers in handling vibrating tools and could decrease the grip force of workers.

\section{Conclusions}

In summary, the determination of significant causeeffect health variables to hand arm vibration symptoms and disorders were separated into two categories which are categorical data and continuous data. An analysis was also conducted to test the significant correlation of categorical and continuous cause variables to hand arm symptoms and disorders. For categorical symptoms, an analysis selection revealed that the work repeatedly done with the forearms and hands with twisting movement shown significant medium association (Spearman correlation $=0.599 ; \mathrm{p}=0.000$ ) for neurological symptoms. For continuous disorders, the most high significant correlation cause-effect is height for right hand grip strength (Pearson correlation $=0.392 ; \mathrm{p}=0.000$ ), weight for left hand grip strength (Pearson correlation $=0.353$; $\mathrm{p}=0.000$ ), age for right hand numerical scoring (Pearson correlation $=0.386 ; \mathrm{p}=0.000$ ) and working experience for left hand numerical scoring (Pearson correlation $=0.337$; $\mathrm{p}=0.000$ ). The continuous cause-effect variables have covered an occupational diseases originating from hand arm vibration exposure such as loss of hand grip strength and finger blanching. In categorical symptoms, the work repeatedly was the most significant cause variables associated to neurological, musculoskeletal and awareness symptoms. In continuous data, the height, weight, estimated right hand daily vibration exposure, age and working experience were the significant cause 
variables associated to loss of hand grip strength and finger blanching.

\section{References}

1. M. Bovenzi, Exposure-response relationship in the hand-arm vibration syndrome: an overview of current epidemiology research. Int Arch Occup Environ Health, 71, pp. 509-519 (1998)

2. M. J. Griffin, Measurement, evaluation, and assessment of occupational exposure to handtransmitted vibration. Occupational and Environmental Medicine, 54, pp. 73-89 (1997)

3. D. J. Edwards \& G. D. Holt, Exposure to hand-arm vibration: implications of new statutory requirements. Building Research \& Information, 33(3), pp. 257-266 (2005)

4. R. Cederlund, S. Iwarsson \& G. Lundborg, Quality of life in Swedish workers exposed to hand-arm vibration. Occupational Therapy International, 14(3), pp. 156-169 (2007)

5. J. Friden, Vibration damage to the hand: Clinical presentation, prognosis and length and severity of vibration required. Journal of Hand Surgery, 26B(5), pp. 471-474 (2001)

6. N. J. Mansfield, Human Response to Vibration. United Kingdom: CRC Press LLC (2005)

7. K. F. Chan, C. W. C. Tan, D. S. C. Yeo, H. S. K. Tan, F. L. Tan, E. W. Tan, G. P. Y. Szeto \& A. S. K. Cheng, Occupational Rehabilitation in Singapore and Malaysia. Journal Occupational Rehabilitation, 21, pp. 69-76 (2011)

8. M. Widia \& S. Z. M. Dawal, The effect of handheld vibrating tools on muscle activity and grip strength. Australian Journal of Basic and Applied Sciences, 5(11), pp. 198-211 (2011)

9. T. A. Su, V. C. W. Hoe, R. Masilamani, \& A. B. Awang Mahmud, Hand-arm vibration syndrome among a group of construction workers in Malaysia. Occup. Environ. Med., 68(1), pp. 58-63 (2011)

10. S. B. M. Tamrin, M. N. Jamalohdin, Y. G. Ng, S. Maeda \& N. A. M. Ali, The characteristics of vibrotactile perception threshold among shipyard workers in a tropical environment. Industrial Health, 50, pp. 156-163 (2012)

11. S. R. Kamat, H. Norhidayah, I. Halim \& H. C. Hui, Effect of working posture and hand grip for carpal tunnel syndrome among aerospace workers. International Journal of Mechanical \& Mechatronics Engineering, 14(1), pp. 1-6 (2014)

12. A. T. Su, S. Maeda, J. Fukumoto, N. Miyai, M. Isahak, A. Yoshioka, R. Nakajima, A. Bulgiba \& K. Miyashita, A cross sectional study on hand-arm vibration syndrome among a group of tree fellers in a tropical environment. Industrial Health, 52, pp. 367-376 (2014)

13. R. Sauni, R. Paakkonen, P. Virtema, V. Jantti, M. Kahonen, E. Toppila, I. Pyykko \& J. Uitti,
Vibration-induced white finger syndrome and carpal tunnel syndrome among Finnish metal workers. Int Arch Occup Environ Health, 82, pp. 445-453 (2009)

14. Y. H. Ko, L. E. Ooi, \& Z. M. Ripin, The design and development of suspended handles for reducing hand-arm vibration in petrol driven grass trimmer. International Journal of Industrial Ergonomics, 41, pp. 459-470 (2011)

15. A. J. Brammer, W. Taylor \& G. Lundborg, Sensorineural stages of the hand-arm vibration syndrome. Scand. J. Work Environ Health, pp. 279283 (1987)

16. Vibration Injury Network Guidelines for Hand Transmitted Vibration for Health Surveillance. Appendix H1A: European Committee. (2011)

17. R. Paakkonen, R. Sauni, J. Uitti \& E. Toppila, Evaluation of hand-transmitted vibration exposure on basis of a questionnaire. Proc. of the Acoustics Conference. Paris. Euronoise. pp. 2235-2238 (2008)

18. Y. Soo, M. Sugi, H. Yokoi, T. Arai, R. Kato \& J. Ota, Quantitative estimation of muscle fatigue on cyclic handgrip tasks. International Journal of Industrial Ergonomics, 42, pp. 103-112 (2012)

19. J. Jang, S. Kim, S. K. Park, J. Roh, T. Lee \& J. T. Youn, Quantitative Exposure Assessment for Shipyard Workers Exposed to Hand-Transmitted Vibration From a Variety of Vibration Tools. America Industrial Hygiene Association (AIHA) Journal, 63, pp. 305-310 (2002)

20. M. Dado, R. Hnilica, J. Kovac \& M. Kucera, Assessment of Hand-transmitted Vibration During Work With Chain Saw. Proceeding of the 22nd International DAAAM Symposium, 22(1) (2011)

21. M. J. Griffin, Foundations of hand-transmitted vibration standards. Nagoya Journal Medical Science, 57, pp. 147-164 (1994)

22. M. J. Griffin, Negligent exposure to handtransmitted vibration. Int. Arch. Occup. Environ. Health, 81(5), pp. 645-659 (2008)

23. K. Poole \& H. Mason, Relationship between selfreported upper limb disability and quantitative tests in hand-arm vibration syndrome. Disability and Rehabilitation, 29(5), pp. 359-366 (2007)

24. F. M. Moy, E. W. H. Chang \& K. W. Kee, Predictors of handgrip strength among the free living elderly in rural Pahang, Malaysia. Iranian J Publ Health, 40(4), pp. 44-53 (2011).

25. T. Kamarul, T. S. Ahmad, \& W. Y. C. Loh, Hand grip strength in the adult Malaysian population. Journal of Orthopedic Surgery, 12(2), pp. 172-177 (2006)

26. K. Seri Rahayu, A. Nurulhuda \& A. Rohana, Vibration of power hand tool and discomfort experience among malaysian industrial workers. Proc. of 2th International Conference on Ergonomics, Universiti Malaya (2013) 